\title{
DA IMPOSSIBILIDADE DA PRONÚNCIA SER LASTREADA UNICAMENTE NA PALAVRA DO DELATOR
}

THE IMPOSSIBILITY OF PRONUNCIATION TO BE LASTREATED ONLY IN THE DELATOR'S WORD

\section{Clóvis Alberto Volpe Filho'}

ISSUE DOI: $10.21207 / 1983.4225 .348$

\section{RESUMO}

O presente artigo analisa a delação premiada (ou colaboração premiada) como meio de prova, destacando suas limitações no ordenamento jurídico, especificamente no caso do rito do Tribunal do Júri, o qual prevê a decisão de pronúncia como aquela que determina a submissão do réu a julgamento perante o Conselho de Sentença. Em verdade, pretende-se verificar a (in)validade da decisão de pronúncia estar fundamentada unicamente na delação de um dos agentes, tendo em vista que tal decisório não exige o exaurimento do mérito.

Palavras-chave: Delação premiada. Tribunal do Júri. Meio de prova. Decisão de pronúncia.

\footnotetext{
${ }^{1}$ Possui graduação em Direito pela Faculdade de Direito de Franca (2003), mestrado em Direito Constitucional pela Universidade de Franca (2005), especialização em Ciências Criminais pela Puc-Minas (2011) e MBA em Direito Empresarial pela FGV (2011). Atualmente é Doutorando em Direito Constitucional pela FADISP, advogado e professor da graduação da Fafram/Ituverava e da Faculdade de Direito de Franca. Tem experiência na área de Direito, com ênfase em Direito Constitucional, Direito Penal e Direito Processual Penal. Foi pesquisador/bolsista durante a graduação pela Fapesp, e durante o mestrado pesquisador/bolsista pela Capes.
} 


\section{ABSTRACT}

This article analyzes the awarding of a prize (or prize-winning collaboration) as a means of proof, highlighting its limitations in the juridical order, specifically in the case of the jury court, which provides for the pronouncement of pronouncement as the one determining the defendant's submission to Judgment before the Board of Appeal. In fact, it is intended to verify the (in) validity of the pronouncement of pronouncement to be based solely on the delation of one of the agents, since such a decision does not require the exhaustion of merit.

Keywords: Awarded praise. Jury court. Means of proof. Decision to pronounce.

\section{INTRODUÇÃO}

A delação premiada (ou colaboração premiada), face aos recentes acontecimentos políticos e jurídicos do Brasil, que certamente não são circunstanciais e devem deixar forte rastro na história, é tema em destaque para os estudiosos das ciências criminais. Ocorre que sua regulamentação mais verticalizada é contemporânea, datada de 2013, com a edição da Lei 12.850, que, entre outras coisas, definiu a organização criminosa e dispôs sobre a investigação criminal e os meios de obtenção da prova; assim, faz-se necessário analisar os reflexos que esse instituto acarreta no ordenamento jurídico penal.

No presente artigo, pretende-se analisar a harmonia ou o conflito existente entre a delação premiada (declarações do agente colaborador) como meio de prova e a decisão de pronúncia. Em outras palavras, a problematização concentra-se na seguinte indagação: é possível pronunciar o acusado com base exclusivamente na declaração do delator?

A resposta não é tão simples. Como será apresentado, a pronúncia é uma decisão interlocutória mista não terminativa, que não analisa o mérito da causa, mas apenas fixa uma classificação penal para ser decidida pelos jurados, ou seja, delimita a acusação e submete o réu a julgamento em plenário.

Nesse contexto, a Lei Processual Penal exige apenas, quanto à autoria, indícios suficientes para a pronúncia do réu. Assim, a questão é 
saber se a delação premiada, embora não seja suficiente para embasar a condenação, seria para fundamentar a pronúncia.

Antes de iniciar as exposições relativas ao tema, imperioso se torna comentar sobre a sua delimitação. $\mathrm{O}$ tema, atinente à incriminação feita por um dos réus ao outro, já é de bastante conhecimento na doutrina ${ }^{2}$ e na jurisprudência. Tanto que não faltam julgados sobre o assunto, apontando para impossibilidade de se condenar quando restar nos autos somente a delação do comparsa. ${ }^{3}$ A proposta deste artigo é verificar se a delação do agente colaborador, fornecida nos limites da Lei n. 12.850/13, é suficiente para a pronúncia. A delação premiada, nos moldes como arquitetada pela referida lei, pode trazer uma série de questionamentos, inclusive sobre sua aplicabilidade no rito do júri. Porém, o presente artigo está limitado à utilização das declarações do agente colaborador como meio de prova para a decisão de pronúncia, não versando sobre outras consequências do instituto da colaboração premiada no Tribunal do Júri, que certamente serão objetos de diversas discussões acadêmicas.

\section{DECISÃO DE PRONÚNCIA}

Como é cediço, o procedimento do júri possui duas fases: a primeira denominada de Judicium Accusationis, iniciando-se com a denúncia e encerrando-se na decisão de pronúncia; já a segunda, chamada de Judicium Causae, tem como marco inicial a pronúncia e como término a decisão final do Conselho de Sentença.

\footnotetext{
2 MALATESTA, Nicola Framarino Dei. A lógica das provas em matéria criminal. Tradução de Paolo Capitanio. Campinas: Bookseller, 2001; CARMAGO ARANHA, Adalberto José Q. T. de. Da prova no processo penal. 3. ed. São Paulo: Ed. Saraiva, 1994; ROSSETO, Enio Luiz. A confissão no processo penal. São Paulo: Atlas, 2001; LIMA, Camile Eltz de e CARVALHO, Salo. Delação Premiada e confissão: filtros constitucionais e adequação sistemática. Revista jurídica, v. 57, nº 385, nov. 2009.

3 "Se a própria confissão do acusado, auto-incriminando-se, não é probatio probantissima, em face do preceito do art. 197, do CPP, como estabelece a Exposição de Motivos do Código de Processo Penal, não constitui, fatalmente, prova plena de culpabilidade (inc. VII), muito menos servirá, como meio de prova, a indicação de partícipe, em interrogatório, extrajudicial de -réu como testemunho contra outro, ao arrepio das garantias constitucionais do contraditório, ante o impedimento imposto pelo art. 187, do CPP." (TACrimSP, RJD 05/171).
} 
De acordo com o disposto no art. 413, "o juiz, fundamentadamente, pronunciará o acusado, se convencido da materialidade do fato e da existência de indícios suficientes de autoria ou de participação". A pronúncia é, em síntese, a decisão pela qual o juiz declara que o réu será submetido a julgamento pelos jurados por haver indícios da prática de um crime doloso contra a vida.

Vislumbra-se, claramente, que a lei não exige uma certeza da autoria delitiva, posto que condicionou a uma probabilidade quanto ao autor do crime. É dizer que, ao passo que precisa da prova sobre a existência da infração penal (materialidade), basta um indicativo qualificado sobre a autoria delitiva. Mesmo por que, do contrário restaria afrontada a Constituição, que prevê a soberania do veredicto e a competência dos jurados para o julgamento de crimes dolosos contra a vida (art. $5^{\circ}$, XXXVIII, alínea "c" e "d").

Pode-se afirmar que a decisão de pronúncia é cirúrgica, na medida em que deve ter uma motivação idônea, sob pena de nulidade (art. 93, IX da Constituição), mas que não avance para juízos meritórios, pois esse campo compete aos jurados analisarem. Nas linhas da doutrina:

A sentença de pronúncia deve ser redigida em linguagem serena, sem as influências perturbadoras da isenção da Justiça. A sentença de pronúncia deve ser sucinta, precisamente para evitar a sugestiva influência ao Júri. A pronúncia deve ser lançada em termos sóbrios e comedidos a fim de não exercer qualquer influência no ânimo dos Jurados. Não pode o juiz antecipar-se ao julgamento do Tribunal do Júri com uma interpretação definitiva e concludente da prova em favor de uma das versões existentes nos autos. O juízo de comparação e escolha de uma das viabilidades decisórias cabe ser feito pelos Jurados e não pelo juiz da pronúncia. ${ }^{4}$

Daí serem necessários apenas indícios suficientes de autoria, para que o réu seja submetido a julgamento do júri pelo crime anotado na decisão de pronúncia. O juiz deve limitar sua fundamentação na indicação

\footnotetext{
${ }^{4}$ MARREY, Adriano; FRANCO, Alberto Silva e STOCO, Rui. Teoria e Prática do Júri. 7. ed. São Paulo: Revista dos Tribunais, 2000. p. 159.
} 
da materialidade do fato e no apontamento da existência de indícios suficientes de autoria ou de participação, devendo, após, declarar o dispositivo legal em que julgar incurso o acusado e especificar as circunstâncias qualificadoras e as causas de aumento de pena, se o caso (art. 413, parágrafo $1^{\circ}$, do Código de Processo Penal).

Como salienta Antônio Magalhães Gomes Filho (2001, p. 231), "nessa decisão, tipicamente processual, o juiz não realiza uma cognição exauriente a respeito dos temas de fato e de direito discutidos na causa, até porque isso significaria invadir indevidamente a competência constitucional que é do tribunal popular...". 5

Tecnicamente, e segundo a classificação das decisões jurisdicionais, trata-se de uma decisão interlocutória mista não terminativa, que declara a admissibilidade da acusação, frente à prova da materialidade e o indício suficiente de autoria, para que os jurados decidam o mérito da causa. É a chamada "sentença processual" que, após análise das provas do processo, declara admissível a acusação a ser desenvolvida em plenário. ${ }^{6}$ Logo, a pronúncia contempla um juízo de prelibação, tendo natureza processual e não produzindo coisa julgada.

Será necessário, então, saber se essa análise sumária, não exauriente, realizada quando da pronúncia, pode ter arrimo exclusivamente na delação premiada; antes, porém, alguns aspectos desse instituto necessitam de abordagem.

\section{DELAÇÃO PREMIADA COMO MEIO DE PROVA}

O conceito da delação premiada, atualmente denominada de colaboração premiada, em uma clara tentativa de retirar aspectos pejorativos desse instituto, é fornecido por Eduardo Araújo da Silva:

A colaboração premiada, também denominada de cooperação processual (processo cooperativo), ocorre quando o acusado, ainda na fase de

\footnotetext{
5 GOMES FILHO Antonio Magalhães. A motivação das decisões penais. São Paulo: Revista dos Tribunais, 2001, p. 231.

${ }^{6}$ CAMPOS, Walfredo Cunha. Tribunal do júri - teoria e prática. São Paulo: Atlas, 2010, p. 60.
} 
investigações criminal, além de confessar seus crimes para as autoridades, evita que outras infrações venham a se consumar (colaboração preventiva), assim como auxilia concretamente a polícia na sua atividade de recolher provas contra os demais coautores, possibilitando suas prisões (colaboração repressiva). ${ }^{7}$

Denota-se que a expressão "delação premiada" revela de forma mais precisa o meio de que se valeu o agente para o alcance de um prêmio, ou seja, o instrumento (entrega de comparsas, entre outras coisas) utilizado para o alcance de um fim (benefícios ao acusado); enquanto a colaboração premiada está mais vinculada com o fim objetivado pelo Estado (auxílio na investigação), isto é, a efetiva participação no deslinde da investigação penal recebendo em razão disso benefícios.

Em que pese o enfoque de cada expressão, ao fim e ao cabo, todas revelam a mesma coisa: a colaboração (ou delação) premiada ocorre quando o investigado, ao prestar suas declarações, coopera com as atividades da persecução criminal, pois além de confessar crimes, indicar comparsas, apresentar provas e auxiliar na elucidação do delito, dentro dos limites estipulados em um acordo homologado pelo juiz, recebendo pela cooperação eficaz benefícios de ordem penal ou processual penal.

Ainda que em breve linhas, necessário se faz pontuar que a chamada "negociação penal" ganhou novos e mais sólidos contornos com a Lei n. 12.850/13, como bem lembrou Eugênio Pacelli:

Mas não se pode negar que a Lei $\mathrm{n}^{\circ} 12.850 / 13$ pretende instituir uma modalidade de negociação penal, com parcial flexibilização do princípio da obrigatoriedade da ação penal, com contornos mais complexos que aquele previsto na conhecida transação penal da Lei $\mathrm{n}^{\circ}$ 9.099/95. Diferença perfeitamente explicável: esta última cuida de infrações penais de menor potencial ofensivo, enquanto a outra, a primeira, trata de organizações

${ }^{7}$ DA SILVA, Eduardo Araujo. Organizações Criminosas - aspectos penais e processuais da lei n. 12.850/13. 2. ed. Atas: São Paulo, 2015, p. 53. 
criminosas, associadas, em regra, a crimes de maior relevância jurídico-penal. ${ }^{8}$

A colaboração premiada é um instrumento que não pode ser valorado a priori, ou seja, não pode ser qualificado como útil, lícito ou eficaz (nem mesmo os opostos), antes de se obter a delação, entender a forma da obtenção e os resultados dali originados. Toda delação premiada está, portanto, sujeita a um crivo de utilidade, licitude e eficácia. Utilidade enquanto análise da fase investigatória, perquirindo se será proveitosa aquela colaboração na fase que a investigação se encontra; licitude para se verificar se foi obtida sem nenhum vício de consentimento ou afronta às formas legais; eficácia no sentido do alcance da elucidação dos fatos enquanto meio de prova, bem como fonte para obtenção de outras provas.

Interessa para o presente artigo os limites da delação premiada enquanto meio de prova. Há um dispositivo legal que baliza a utilização da delação como meio de prova, qual seja, o art. $4^{\circ}$, parágrafo 16 , da Lei n. 12.850/2013, que assim prescreve: "Nenhuma sentença condenatória será proferida com fundamento apenas nas declarações de agente colaborador."

Em verdade, trata-se de uma confirmação do sistema da persuasão racional e relativa, que pretende excluir a íntima convicção, bem como eliminar provas previamente tarifadas pelo legislador. Esse ponto fornece um indicador para o entendimento da natureza da delação premiada: não há (ou não deveria haver) provas absolutas no processo penal brasileiro, pois, nem mesmo a confissão serve, por si só, para fundamentar a condenação do réu (art. 197, do Código de Processo Penal).

Ao impedir que haja decisão com base na delação, o legislador visou à justiça. Destaca-se um trecho do acórdão da lavra do Ministro Celso de Mello (Petição 5.700, DF), o qual expõe as razões da limitação do valor probatório da delação premiada:

Com tais providências, o legislador brasileiro procurou neutralizar, em favor de quem sofre a imputação emanada de agente colaborador, os mesmos efeitos perversos da denunciação caluniosa

\footnotetext{
${ }^{8}$ OLIVEIRA, Eugênio Pacelli. Curso de processo penal. 18. ed. São Paulo: Atlas, 2014, p. 836 .
} 
revelados, na experiência italiana, pelo "Caso Enzo Tortora" (na década de 80), de que resultou clamoroso erro judiciário, porque se tratava de pessoa inocente, injustamente delatada por membros de uma organização criminosa napolitana ("Nuova Camorra Organizzata") que, a pretexto de cooperarem com a Justiça (e de, assim, obterem os benefícios legais correspondentes), falsamente incriminaram Enzo Tortora, então conhecido apresentador de programa de sucesso na RAI ("Portobello').

A legislação atual pretende que o delator apresente outras provas além de suas declarações, pois se somente essas restarem dentro do conjunto probatório, não haverá base para condenação da pessoa delatada. Mesmo que haja outras provas, sobre outras pessoas ou crime, a interpretação a ser feita direciona para o necessário arrimo probatório das declarações e apontamentos do delator sobre a pessoa determinada.

Frederico Valdez Pereira assevera que as declarações de corréu não podem, por si só, alterar o estado constitucional de inocência do acusado. ${ }^{9}$ Esse raciocínio amolda-se perfeitamente nas garantias processuais erigidas no Estado Democrático de Direito, não podendo alçar a delação premiada como a "nova rainha das provas", sob pena de, além do trono, surgirem períodos sombrios.

Nesse contexto, o julgador terá que fundamentar a condenação do delatado em outras provas, pois a delação deve ser uma fonte de prova, e não a única prova. Então, seria possível uma pessoa ser condenada com base exclusivamente em uma delação fornecida licitamente em um processo penal? Obviamente que não, devendo existir outros elementos de prova (vide decisão do STF, HC 94034, Relatora Min. Cármen Lúcia).

Caso a palavra do delator contra o acusado venha ilhada, destituída de outras provas, não há que se cogitar na possibilidade dessa delação passar a se revestir de mero testemunho, com valor de prova testemunhal. Ora, a prova testemunhal, ainda que única, pode embasar a sentença condenatória (tome-se como exemplo os crimes contra a dignidade sexual), e com maior razão a decisão de pronúncia.

\footnotetext{
${ }^{9}$ PEREIRA, Frederico Valdez. Valor probatório da colaboração processual (delação premiada). In Revista dos Tribunais, São Paulo, v. 98, n. 879, jan. 2009, p. 475-498.
} 
No entanto, face ao conteúdo do parágrafo $16^{\circ}$, do art. $4^{\circ}$, da Lei n. 12.850/13, a tese defendida, como se verá a seguir, é justamente insuficiente pela limitação da declaração do agente colaborador como meio de prova.

\section{DELAÇÃO PREMIADA COMO ÚNICO FUNDAMENTO DA PRONÚNCIA}

A questão enfrentada parte da premissa de que, contra determinado acusado, não há outra prova a não ser a declaração fornecida pelo delator quando do acordo de colaboração premiada. Nesse tom, o que importa é saber se a pronúncia pode ser fundamentada exclusivamente nas declarações do agente colaborador.

A decisão de pronúncia tem, resumidamente, dupla análise: prova da materialidade delitiva e indício suficiente de autoria. Nas palavras de Renato Brasileiro de Lima, a análise do juiz restringe-se à verificação da presença do fumus boni juris, admitindo todas as acusações que tenham ao menos probabilidade de procedência. ${ }^{10}$

É preciso entender qual o conceito de indício suficiente de autoria, para poder inferir sobre a licitude de a delação premiada ser, por si só, indício suficiente apto a embasar a pronúncia.

A razão para adjetivar o indício com a qualidade de suficiente é justamente por não poder ser submetido ao Tribunal do Júri o réu que, após a instrução, tem contra ele uma frágil prova produzida. Por isso que existe a decisão de impronúncia, que é aquela sacada nos casos em que o juiz não se convence da materialidade do fato ou da existência de indícios suficientes de autoria (art. 414 do CPP).

Em outras palavras: ainda que nesta fase não se possa descer ao mérito, o legislador exige que o juiz verifique se há indícios suficientes para que o réu seja julgado perante o Conselho de Sentença.

Tourinho Filho adverte que "cabe, pois, ao juiz da pronúncia dizer se é caso, ou não, de ser o réu submetido a julgamento popular. E,

\footnotetext{
${ }^{10}$ LIMA, Renato Brasileiro de. Manual de Processo Penal. 2. ed. Salvador: JusPodivum, 2014, p. 1294.
} 
nessa decisão, é preciso muita cautela, muito equilíbrio. Os indícios de autoria devem ser convincentes. Mera suspeita nem sequer é indício..."11

Verifica-se que é um indício qualificado, diferenciado, especial, que possibilite a submissão de um cidadão a julgamento perante seus pares, arcando com todos os constrangimentos sociais daí oriundos. Walfredo Cunha Campos, de certa forma, comunga com este posicionamento, pois declara que não basta, para a pronúncia, ser possível a autoria, devendo haver um plus, pois a autoria deve ser provável, enriquecida a mera possibilidade com provas convincentes da prática criminosas por determinada pessoa. ${ }^{12}$

Poderia ser a incriminação do agente colaborador realizada em sede de delação premiada, por si só, considerada como indício suficiente de autoria para pronúncia do acusado? A análise depende do entendimento de qual seria a consequência caso fosse possível aceitar a colaboração premiada como único fundamento da autoria delitiva.

Caso o juiz pronunciasse o acusado com base tão somente na colaboração premiada, os jurados poderiam condená-lo com base exclusivamente nessa prova colaborativa, haja vista a desnecessidade de fundamentar a decisão.

A pronúncia, nesse contexto, seria o mesmo que um aval ao Tribunal do Júri para condenar com base exclusivamente na palavra do delator. A soberania dos jurados somente é exercida se houver justa causa para tanto - leia-se materialidade e indícios suficientes de autoria. Considerando como indício suficiente de autoria a delação premiada, o julgador estaria autorizando os jurados a decidirem, ainda que seja para condenar, com base unicamente na delação premiada, descumprindo a proibição de condenação estar lastreada tão somente na colaboração premiada por uma via oblíqua.

Não se pode alegar que para a pronúncia não precisa de uma "certeza", bastando elementos aptos a gerar dúvida razoável no espírito do julgador, como salienta Guilherme $\mathrm{Nucci}^{13}$, isto porque, ainda que o julgador tenha dúvida, essa não aflora de uma fonte válida para a decisão,

11 TOURINHO FILHO, Fernando da Costa. Manual de Processo Penal. 15. ed. São Paulo: Saraiva, 2012, p. 761.

12 CAMPOS, Walfredo Cunha. Tribunal do júri - teoria e prática. São Paulo: Atlas, 2010. p. 63.

${ }^{13}$ NUCCI, Guilherme de Sousa. Código de Processo Penal Comentado. 11. Ed., Revista dos Tribunais, 2012, p. 808. 
por haver um impeditivo legal a possibilitar que haja condenação com base na unicamente na delação.

É dizer: embora haja dúvida sobre a autoria delitiva, a delação não pode ser caracterizada como indício suficiente de autoria, justamente pelo risco do acusado ser condenado pelo Conselho de Sentença utilizando-se a colaboração premiada como fundamento exclusivo.

O sistema jurídico não possibilita aos jurados, embora soberanos na análise dos crimes dolosos contra a vida, uma decisão sem limites. Os jurados, por exemplo, não podem condenar com base em uma prova ilícita, e se o fizerem, certamente o Tribunal de Justiça anulará o julgamento.

Um raciocínio contrário culminar-se-ia no absurdo de os crimes dolosos contra a vida estarem imunes às regras de limitação da prova, seja em relação à confissão, ou mesmo da delação e da prova ilícita. O princípio da soberania dos jurados (alínea "c", inciso XXXVIII do art. $5^{\circ}$ da Constituição Federal) em nada se relaciona com o aqui aventado, haja vista que tal soberania somente vem à baila quando da segunda fase, após a decisão de pronúncia.

A partir do momento em que o réu é pronunciado, há uma mensagem clara do judiciário, a saber: senhores jurados, a decisão de mérito do crime contra a vida, que dispõem tem competência constitucional reservada, independente da rasa instrução que possa ocorrer em plenário, pode ser tanto de condenação, como de absolvição, pois há base para ambas.

Caso assim não fosse, qual sentido teria a existência da decisão de impronúncia? O sistema concebido como bifásico é justamente para que, na primeira fase, haja admissibilidade da acusação, tanto que é denominado de juízo da formação da acusação ou da culpa. Segundo José Frederico Marques, o objetivo dessa primeira fase é o de esclarecer se existe contra o acusado suspeita de fato que seja suficiente para colocá-lo perante o tribunal de julgamento. ${ }^{14}$ É dizer: somente será admissível uma acusação se essa, quando da decisão de pronúncia, possibilitar que haja uma eventual e futura condenação pelos jurados, do contrário, o magis-

\footnotetext{
${ }^{14}$ MARQUES, José Frederico. A instituição do júri. Atualizado por Hermínio Alberto Marques Porto, José Gonçalves Canosa Neto e Marco Antonio Marques da Silva. Campinas: Booksseller, 1997, p. 348.
} 
trado deve absolver sumariamente, impronunciar ou desclassificar, conforme o caso concreto.

A tese aqui explanada também é aplicável, na íntegra, nos casos em que haja apenas a confissão como elemento caracterizador da autoria delitiva, ou, ainda, quando haja delação sem estar parametrizada pela Lei n. 12.850/13 (delação sem prêmio). Por óbvio que a regra do art. 197 do $\mathrm{CPP}^{15}$ é um limitador da persuasão racional, posto que o juiz não pode condenar uma pessoa se não houver outra prova ou conjunto probatório que confirme a confissão. O filtro da pronúncia é justamente para impedir tais incongruências, daí a razão de se exigirem "indícios suficientes de autoria" e não somente "indícios de autoria".

Há julgados que já decidiram pela impossibilidade de se pronunciar quando a confissão, sem base em outros elementos, era a única prova produzida na primeira fase do rito do júri ${ }^{16}$. Como também há julgados que não aceitam para condenação a incriminação do réu feita pelo comparsa ${ }^{17}$. Assim, a delação premiada deve seguir a mesma sorte, na medida em que, como as outras, não consegue, por si só, guardar rela-

15 Código de Processo Penal. Art. 197. O valor da confissão se aferirá pelos critérios adotados para os outros elementos de prova, e para a sua apreciação o juiz deverá confrontá-la com as demais provas do processo, verificando se entre ela e estas existe compatibilidade ou concordância.

${ }^{16}$ RECURSO EM SENTIDO ESTRITO. JÚRI. HOMICÍDIO QUALIFICADO. ARTIGO $121, \S 2^{\circ}$, II E IV, DO CP. PRONÚNCIA. IRRESIGNAÇÃO DEFENSIVA. É sabido que a confissão do réu tem valor probatório relativo, devendo ser confrontada e confirmada pelo conjunto probatório. No caso dos autos, em que pese o acusado, na Delegacia de Polícia, tenha reconhecido ser o autor do fato, a sua versão não foi confirmada pela prova colhida sob o crivo do contraditório. Nenhuma das testemunhas ouvidas em juízo confirmou ser o réu o autor dos disparos; ao contrário, a testemunha Osmar afirmou que quem efetuou os disparos contra a vítima foi a testemunha Ionara. Ademais, a testemunha Sebastião, no dia do fato, reconheceu Ionara como a autora do homicídio, vindo somente a modificar a sua versão após o depoimento do réu em sede policial, quase quatro meses após o fato. Assim, diante da fragilidade dos indícios de autoria, tenho que é caso de impronúncia. (TJ-RS - RSE: 70053808366 RS, Relator: Osnilda Pisa, Data de Julgamento: 26/06/2013, Primeira Câmara Criminal, Data de Publicação: Diário da Justiça do dia 10/07/2013)

${ }^{17}$ CHAMADA DE CO-RÉU: inidoneidade para lastrear condenação. A chamada de coréu, ainda que formalizada em Juízo, é inadmissível para lastrear a condenação: precedentes. Ausência de elementos de prova válidos para fundamentar a condenação. (STF RHC: 81740 RS, Relator: Min. SEPÚLVEDA PERTENCE, Data de Julgamento: 29/03/2005, Primeira Turma, Data de Publicação: DJ 22-04-2005). 
ção com indício suficiente, além de sofrer limitação legal. Ainda que sejam indícios, não são suficientes para a pronúncia.

A argumentação de que a palavra do comparsa teria valor probatório aproximado ao testemunhal, não merece guarida. A uma, em razão da fragilidade, face ao contexto e as razões pelas quais uma pessoa que pratica crime aponta seu comparsa (imoralidade, vingança e benefícios). A duas, em razão de a própria lei ter determinado que a delação premiada seja insuficiente para a condenação do delatado.

Nesse cenário, parece ser mais acertada a decisão de impronúncia, que é aquela na qual o juiz não se convence da materialidade do fato ou da existência de indícios suficientes de autoria ou de participação (art. 414, do Código de Processo Penal).

Aury Lopes Júnior explana que, quando da decisão de pronúncia, aplica-se a presunção de inocência e o in dubio pro reo, e não o in dubio pro societate, que não possui base constitucional. Para esse autor, somente quando houver fortes elementos probatórios de autoria e materialidade (probabilidade e alto grau de convencimento) pode o juiz pronunciar. Havendo dúvida razoável, deverá impronunciar, se for o caso. ${ }^{18}$

Nos limites do presente artigo, o que se defende é justamente que a delação isolada não é elemento forte o suficiente para embasar a pronúncia; assim, a impronúncia, além de acertada no âmbito legal, é também uma decisão justa, no sentido que impedirá que os jurados se debrucem em um caso com uma única fonte probatória, a qual é estéril no sentido de fundar a condenação.

\section{CONSIDERAÇÕES FINAIS}

A acusação feita pelo agente colaborador, isoladamente, é estéril para embasar a pronúncia, posto que o rito da segunda fase do Tribunal do Júri é tão precário em termos instrutórios, que certamente restará apenas a delação como única prova para eventual condenação.

Além disso, a inexistência de fundamentação do Conselho de Sentença pode ensejar uma condenação tão somente com base na delação (ou na confissão), afrontando a norma do parágrafo 16 , do art. $4^{\circ}$ da Lei 12.850/13 (ou a norma do art. 197 do CPP), que proibe a condenação com

${ }^{18}$ LOPES JR., Aury. Direito Processual Penal. 9. ed. São Paulo: Saraiva, 2012. p. 1002. 
base apenas na colaboração. Portanto, não se pode conceber um sistema que impede a condenação pelo juiz togado quando há somente a colaboração premiada (ou a confissão ou a delação sem prêmio) em crimes comuns, e, na mesma situação, autoriza os juízes leigos a condenarem quando do julgamento de crimes dolosos contra a vida.

Possibilitar, com base no malsinado princípio do in dubio pro societate, que o acusado seja submetido ao Tribunal do Júri tendo como base única a colaboração ou a confissão, é jogar dados com a justiça, pois caso não seja absolvido, restará condenado por uma decisão velada (no sentido de não se exigir fundamentação) certamente pautada pela delação ou por sua confissão. Haverá que se conviver com um paradoxo: os juízes leigos estarão imunes dos limites da fundamentação da condenação impostos pela lei. Ora, se esses limites são justamente para se evitar ilegalidades e injustiças, caso não aplicados no rito do júri, ter-se-á um rito que acoroçoa tais mazelas.

Compreender o sistema bifásico, e principalmente o objetivo da primeira fase denominada juízo da acusação, é fator determinante para a correta interpretação do que vem a ser "indício suficiente de autoria" como requisito para a pronúncia do réu. O judiciário, como guardião maior da Constituição Federal, deve impedir que um cidadão seja conduzido à julgamento perante o Conselho de Sentença quando, pelas provas colhidas, for impossível, face aos critérios legais, emitir um juízo condenatório. O que a primeira fase deve possibilitar é, justamente, uma admissibilidade da acusação, a qual esteja apta a abarcar, ainda que eventualmente, um juízo condenatório quando do mérito. Se não existe base probatória suficiente para condenação do acusado, a pronúncia restará prejudicada.

Em sendo assim, e como conclusão final, por existir impedimento legal para condenação com base unicamente na delação premiada (ou na confissão do autor), deve o julgador se postar como bastião da legalidade, impronunciando o acusado, para que sua sorte não dependa de uma decisão que tem lastro na esfera subjetiva dos jurados.

\section{REFERÊNCIAS BIBLIOGRÁFICAS}

CAMPOS, Walfredo Cunha. Tribunal do júri - teoria e prática. São Paulo: Atlas, 2010. 
CARMAGO ARANHA, Adalberto José Q. T. de. Da prova no processo penal. 3. ed. São Paulo: Saraiva, 1994.

GOMES FILHO Antonio Magalhães. A motivação das decisões penais. São Paulo: Revista dos Tribunais, 2001.

LIMA, Camile Eltz de e CARVALHO, Salo. Delação Premiada e confissão: filtros constitucionais e adequação sistemática. Revista jurídica, v. 57, n⿳⺈ 385, nov. 2009.

LIMA, Renato Brasileiro de. Manual de Processo Penal. 2. ed. Salvador: JusPodivum, 2014.

LOPES JR., Aury. Direito Processual Penal. 9. ed. São Paulo: Saraiva, 2012.

MALATESTA, Nicola Framarino Dei. A lógica das provas em matéria criminal. Tradução de Paolo Capitanio. Campinas: Bookseller, 2001.

MARQUES, José Frederico. A instituição do júri. Atualizado por Hermínio Alberto Marques Porto, José Gonçalves Canosa Neto e Marco Antonio Marques da Silva. Campinas: Booksseller, 1997.

MARREY, Adriano; FRANCO, Alberto Silva e STOCO, Rui. Teoria e Prática do Júri. 7. ed. São Paulo: Revista dos Tribunais, 2000, p. 261

NUCCI, Guilherme de Sousa. Código de Processo Penal Comentado. 11. ed., Revista dos Tribunais, 2012.

OLIVEIRA, Eugênio Pacelli. Curso de processo penal. 18. ed. São Paulo: Atlas, 2014.

PEREIRA, Frederico Valdez. Valor probatório da colaboração processual (delação premiada). In Revista dos Tribunais, São Paulo, v. 98, n. 879, p. 475-498, jan. 2009.

ROSSETO, Enio Luiz. A confissão no processo penal. São Paulo: Atlas, 2001.

SILVA, Eduardo Araujo da. Organizações Criminosas - aspectos penais e processuais da lei n. 12.850/13. 2. ed. Atas: São Paulo, 2015.

TOURINHO FILHO, Fernando da Costa. Manual de Processo Penal. 15. ed. São Paulo: Saraiva, 2012. 
